\title{
ANALISIS PROYEK APLIKASI COSTUMER RELATIONSHIP MANAGEMENT STUDY KASUS XYZ BODYCARE
}

\author{
Irma Suryani $^{1}$, Fadila Andini ${ }^{2}$, Ricky Firmansyah ${ }^{3}$ \\ Sistem Informasi ${ }^{1}$, Sistem Informasi ${ }^{2}$, Sistem Informasi ${ }^{3}$ \\ Fakultas Teknologi Informasi ${ }^{1}$, Fakultas Teknologi Informasi ${ }^{2}$, Fakultas Teknologi Informasi ${ }^{3}$ \\ Universitas Adhirajasa Reswara Sanjaya ${ }^{1}$, Universitas Adhirajasa Reswara Sanjaya ${ }^{2}$, Universitas \\ Adhirajasa Reswara Sanjaya ${ }^{3}$

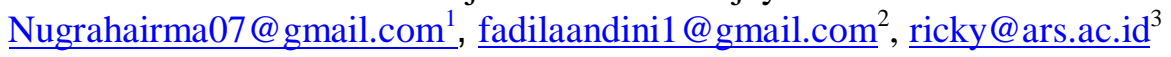

\begin{abstract}
ABSTRAK
Aplikasi Customer Relationship Management (CRM) adalah salah satu dari aplikasi Teknologi Informasi yang merupakan aplikasi strategi bisnis untuk memilih dan menjaga customer, dapat mengoptimalkan nilai jangka panjang, dapat menyimpan filosofi customer centric business dan budaya untuk mendukung efektifitas marketing, sales dan proses servis. Membangun aplikasi Customer Relationship Management (CRM) yang baik harus mengikuti prosedur proyek yang benar yaitu didahului dengan pembuatan proposal untuk menguraikan semua keperluan yang akan diimplementasikan pada pembuatan aplikasi dimaksud. Pada penulisan ini penulis meyusun proposal Aplikasi Customer Relationship Management untuk Xyz BodyCare yang diuraikan secara rinci tentang Ruang lingkup aplikasi yang akan dibangun (Scope), fungsi-fungsi yang akan dibuat yang digambarkan dengan Work Breakdown Structure (WBS), jadwal pelaksanaan, sumber daya, rencana biaya, analisis risiko dan bentuk perubahan manajemen bila aplikasi tersebut siap dioperasikan. Proposal ini diharapkan mampu memberikan masukan untuk membangun aplikasi Customer Relationship Management (CRM) tersebut dan akan diusulkan pada Xyz BodyCare untuk dapat dipakai dan diterapkan.
\end{abstract}

Kata kunci: Analisa Proyek Sistem; Customer Relationship Management; CRM; Sistem Informasi; Xyz BodyCare

Abstract: Customer Relationship Management (CRM) Application is one of the application in IT wich is as the bussiness strategy to choose and keep customer, and it can optimize long Term value, it can save the philosopy of customer centric bussiness and culture to support the effectivity of marketing, sales and the process of customer service. Building the good aplication of Customer Relationship Management (CRM) should follow the right procedure project, which preceded by making the proposal to devide all stuffs that implemented and connected to the process of making the aplication. In this text writer arrange the proposal of application in Customer Relationship Management (CRM) for Xyz BodyCare which devided in detail about the scope of the application that built. The funtions that will be created described by the Work Breakdown Structure (WBS), the schedule, the source, the cost, the analysis of the risk, and the form of management change when the application is ready to operate.This proposal expected to be able to provide input to built the application of Customer Relationship Management (CRM) and will be prosposed to Xyz BodyCare to be used amd applied.

Keywords: System Project Analysis; Customer Relationship Management; CRM; Sistem Informasi; Xyz BodyCare

\section{PENDAHULUAN}

Perkembangan teknologi informasi saat ini sudah menjadi urat nadi bisnis setiap perusahaan, yang tidak saja hanya sekedar pendukung proses bisnis perusahaan tetapi lebih dari itu ialah memegang peranan penting untuk mendrive

JISICOM (Journal of Information System, Informatics and Computing)

http://journal.stmikjayakarta.ac.id/index.php/jisicom Telp.+62-21-3905050, e-mail: jisicom@stmikjayakarta.ac.id, jisicom2017@gmail.com 
proses bisnis suatu perusahaan. Menurut (Fardhani, Rachmawati \& Prabowo, 2016) CRM merupakan sebuah filosofi bisnis yang menggambarkan suatu strategi penempatan client sebagai pusat proses, aktivitas dan budaya.

Aplikasi Customer Relationship Management (CRM) adalah salah satu dari aplikasi Teknologi Informasi yang merupakan sebuah aplikasi strategi bisnis untuk memilih dan menjaga customer agar dapat mengoptimalkan nilai jangka panjang dimana pada CRM membutuhkan filosofi customer centric business dan budaya untuk mendukung efektifitas marketing, sales dan proses servis. Menurut (Wildyaksanjani \& Sugiana) Pelayanan merupakan faktor yang sangat penting bagi perusahaan, terutama bagi perusahaan yang bergerak dalam bidang jasa.

Xyz BodyCare adalah one stop shopping untuk perawatan tubuh pria. yang memiliki 3 pusat perawatan tubuh di Jakarta, 1 di Bandung, dan 1 di Surabaya. Layanan pada Xyz BodyCare ini tidak hanya sekedar layanan pangkas rambut semata, melainkan juga creambath, facial, massage, predicure dan manicure. Dalam melakukan proses bisnisnya sering ditemukan masalah misalnya para bodycare consultant di Xyz BodyCare sangat sulit untuk proaktif mengingatkan pelanggannya. Mereka tidak memiliki informasi yang memuat jadwal lengkap mengenai riwayat perawatan tubuh seorang pelanggan tertentu. Bahkan, jika si pelanggan sudah sampai ke tempat Xyz BodyCare, kadang-kadang para bodycare consultant harus bertanya kembali mengenai perawatan yang akan dilakukan, perawatan apa yang pernah dilakukan sebelumnya, kapan dilakukan, produk- produk apa saja yang dipergunakan dan sebagainya. Untuk memberikan solusi tersebut diatas maka pihak manajemen Xyz BodyCare seharusnya memiliki informasi yang memuat jadwal lengkap mengenai riwayat perawatan tubuh seorang pelanggan tertentu, informasi produkproduk yang pernah digunakan dan riwayat jumlah belanja para pelanggannya hal tersebut dapat meningkatkan pelayanan yang diberikan oleh $\mathrm{Xyz}$ BodyCare kepada pelanggannya lebih profesional, dan proaktif.

\subsection{Tujuan}

1. Para bodycare consultant pada PT Xyz salon BodyCare bisa melihat informasi riwayat perawatan tubuh seorang pelanggan, bisa melihat jadwal perawatan sebelumnya, dari situ dapat dengan mudah mempelajari pola perawatan tubuh si pelanggan tersebut, dan secara proaktif bisa mengingatkan si pelanggan untuk segera melakukan perawatan tubuh kembali jika jadwalnya sudah tiba.

2. Para bodycare consultant pada PT Xyz salon BodyCare bisa melihat informasi mengenai produk-produk yang pernah dipergunakan oleh seorang pelanggan (cream facial, cat rambut, cream untuk creambath,shampoo, dan sebagainya), ada catatan tentang produk yang cocok, juga catatan tentang produk yang tidak cocok alias menimbulkan alergi bagi pelanggan, serta riwayat alergi si pelanggan, supaya terhindar/tidak memberikan produk yang tidak cocok.

3. Para bodycare consultant pada PTXyz salon BodyCare bisa melihat informasi berapa uang yang dibelanjakan oleh seorang pelanggan dalam satubulan di Xyz BodyCare, sehingga dapat diketahui tingkat kemapanan ekonomi pelanggan tersebut. Ini diperlukan untuk menawarkan berbagai produk lain yang relevan. Siapa tahu pelanggan tersebut berminat.

JISICOM (Journal of Information System, Informatics and Computing)

http://journal.stmikjayakarta.ac.id/index.php/jisicom Telp.+62-21-3905050, e-mail: jisicom@stmikjayakarta.ac.id, jisicom2017@gmail.com 
1.3 Ruang Lingkup

1. Meneliti prosedur-prosedur, data-data dan laporan yang berhubungan dengan penjualan jasa (perawatan) dan penjualan produk.

2. Menganalisis operasional, perencanaan dan data-data yang berhubungan dengan penjualan jasa (perawatan) dan penjualan produk.

3. Merancang sistem informasi yang dapat mendukung semua operasional penjualan jasa (percatan) dan penjualan produk.

4. Membuat program komputer untuk sistem informasi CRM perusahaan.

5. Menerapkan/mengimplementasikan serta melakukan pengujian terhadap

\section{TINJAUAN PUSTAKA}

\subsection{Sistem}

Apa yang dimaksud dengan sistem (system)? Secara umum sistem adalah suatu kesatuan, baik obyek nyata atau abstrak yang terdiri dari berbagai komponen atau unsur yang saling berkaitan, saling tergantung, saling mendukung, dan secara keseluruhan bersatu dalam satu kesatuan untuk mencapai tujuan tertentu secara efektif dan efisien.Secara etimologis, istilah "sistem" berasal dari bahasa Latin (systēma) dan bahasa Yunani (sustēma) yang sering dipakai untuk memudahkan dalam menggambarkan interaksi di dalam suatu entitas.Istilah "sistem" sering digunakan dalam berbagai bidang, sehingga maknanya akan berbedabeda sesuai dengan bidang yang dibahas. Namun, secara umum kata "sistem" mengacu pada sekumpulan benda yang saling memiliki keterkaitan satu sama lainnya.

\subsection{Informasi}

Informasi adalah sebuah sekumpulan data ataupun juga fakta yang telah diproses maupun dikelola sedemikian rupa sehingga akan menjadi sesuatu yang mudah dimengerti dan bermanfaat bagi pembacanya.Secara etimologis istilah "informasi"juga berasal dari bahasa Latin, yakni "Informatinem" yang artinya ide, kode, ataupun garis besar. Informasi dapat disajikan maka dalam beragam bentuk, mulai dari tulisan, gambar, tabel, diagram, audio, video,atau yang lain sebagainya.

\subsection{Customer Relationship Management (CRM)}

CRM adalah sebuah pendekatan baru dalam mengelola hubungan korporasi dengan pelanggan pada level bisnis sehingga dapat memaksimumkan komunikasi dan pemasaran melalui pengelolaan berbagai kontak yang berbeda. Pendekatan ini memungkinkan untuk mempertahankan pelanggan dan memberikan nilai tambah secara terusmenerus kepada pelanggan. CRM (Customer Relationship Management) mengombinasikan kebijakan, proses, dan strategi yang diterapkan perusahaan menjadi satu kesatuan yang digunakan untuk melakukan interaksi dengan pelanggan dan juga untuk menelusuri informasi pelanggan. Saat ini, implementasi CRM hampir selalu menggunakan teknologi informasi untuk menarik pelanggan baru yang menguntungkan, hingga mereka memiliki keterikatan pada perusahaan.

\subsubsection{Tujuan Customer Relationship Management}

1. Meningkatkan hubungan antara perusahaan dengan pelanggan yang sudah ada untuk meningkatkan pendapatan perusahaan.

2. Menyediakan informasi yang lengkap mengenai pelangganuntuk memaksimalkan jalinan hubungan pelangan denga perusahaan melalui penjualan secara up selling dan cross 
selling, sehingga dapat meningkatkan keuntungan dengan cara mengidentifikasi, menarik serta mempertahankan pelanggan yang paling memberikan nilai tambah bagi perusahaan.

3. Menggunakan informasi yang terintegrasi untuk menghasilkan pelayanan yang memuaskan dengan memanfaatkan informasi pelanggan untuk memenuhi kebutuhan pelanggan sehingga dapat menghemat waktu pelanggan.

4. Menghasilkan konsistensi dalam prosedur dan proses menyalurkan jawaban kepada pelanggan.

\subsubsection{Manfaat Customer Relationship Management}

- CRM mampu membentuk sebuah loyalitas dari pelanggan

bagi setiap pemilik usaha, loyalitas dari seorang pelanggan adalah salah satu hal yang pasti ingin anda capai. Denganmemanfaatkan CRM, anda akan belajar mengenai bagaimana caranya mengelola pelanggan dengan efektif agar tercipta sebuah loyalitas antara bisnis anda dengan para pelanggan. Dengan menggunakan semua channel yang anda miliki, seperti web, media sosial, contact center, pelayanan, hingga staff sales anda, anda bias memberikan informasi serta pelayanan terbaik kepada pelanggan. Kemudahan akses serta konsistensi yang Anda berikan akan meningkatkan tingkat kepuasan mereka sehingga sedikit demi sedikit loyalitas serta kepercayaan akan terbangun.

- Meningkatkan profit perusahaan

Jika penerapan CRM dimanfaatkan dengan baik, anda bias mendapatkan insight yang berguna mengenai apa yang pelanggan butuhkan hingga tren apa yang sedang berkembang. Dengan begitu, anda dapat dengan segera memikirkan keputusan apa yang harus anda ambil selanjutnya. Dengan insight yang anda sudah dapatkan, bukan tidak mungkin jika keputusan yang anda lakukan dapat meningkatkan penjualan. Selain itu, jika anda sudah mengetahui apa yang diinginkan para pelanggan, anda dapat mengurangi resiko menurunnya kualitas pelayanan Anda dan meminimalisir kerugian.

- Memperoleh informasi pelanggan

Di zaman yang bergerak serba cepat ini, data adalah segalanya. Bahkan, banyak perusahaan yang rela membayar mahal kepada perusahaan lain untuk memperoleh data-data yang dibutuhkan untuk melakukan keputusan atau gebrakan bisnis terbaru.

Melalui CRM, Anda bisa mendapatkan informasi atau data penting dari pelanggan anda, mulai dari sebatas nama, nomor telepon, dan alamat email, hingga ke hal yang lebih kompleks seperti interest serta produk apa yang paling sering dibeli mereka. Salah satu kegunaannya adalah untuk mendapatkan feedback dari para pelanggan serta meningkatkan strategi pemasaran anda dengan mencocokkannya pada profil mereka.

- Proses operasional jadi lebih terstruktur dan efisien

CRM juga dapat memungkinkan anda memiliki sistem yang lebih terorganisir. Sistem yang lebih rapi ini akan meningkatkan efisiensi perusahaan sehingga dapat mengurangi anggaran- anggaran yang seharusnya tidak diperlukan.

\subsubsection{Tujuan Perancangan Proyek}

1. Para consultant pada PT. Xyz Salon bisa melihat informasi riwaya tperawatan tubuh seorang pelanggan, bias melihat jadwal perawatans ebelumnya, dari situ dapat dengan mudah mempelajari pola perawatan tubuh si pelanggan tersebut, dan secara proaktif bias mengingatkan si

JISICOM (Journal of Information System, Informatics and Computing)

http://journal.stmikjayakarta.ac.id/index.php/jisicom Telp.+62-21-3905050, e-mail: jisicom@stmikjayakarta.ac.id,jisicom2017@gmail.com 
pelanggan untuk segera melakukan perawatan tubuh kembali jika jadwalnya sudah tiba.

2. Para consultant pada PT. Xyz bisa melihat informasi mengenai produk- produk yang pernah dipergunakan oleh seorang pelanggan (cream facial, cat rambut, cream untuk creambath, shampoo, dan sebagainya), ada catatan tentang produk yang cocok, juga catatan tentang produk yang tidak cocok alias menimbulkan alergi bagi pelanggan, serta riwayat alergi si pelanggan, supaya terhindar/tidak memberikan produk yang tidak cocok.

3. Para consultant pada PT. Xyz bias melihat informasi berapa uang yang dibelanjakan oleh seorang pelanggan dalam satu bulan di PT. Xyz, sehingga dapat diketahui tingkat kemapanan ekonomi pelanggan tersebut. Ini diperlukan untuk menawarkan berbagai produk lain.

\section{METODE PENELITIAN}

\subsection{Objek Penelitian}

Penelitian ini dilakukan pada perancangan aplikasi CRM (Customer Relationship Management) pada Xyz Body Care.

\subsection{Metode Pengumpulan Data}

Melibatkan pengumpulan (capture), penyimpanan, ekstraksi, pemrosesan, interpretasi, dan laporan dari data-data customer. Data-data tersebut kemudian dianalisis sesuai kebutuhan, misalnya menghubungkan transaksi-transaksi yang tersimpan dengan Analytical CRM.

\subsection{Diskusi Interaktif}

Dalam proses pengumpulan dan penyusunan instrument data ini dilakukan dengan cara melakukan diskusi dan tanya jawab yang dilakukan oleh peneliti dengan pihak - pihak terkait di dalam pihak yang berwenang pada Xyz BodyCare mengenai masalah yang dihadapi, struktur organisasi $X y z$ BodyCare, proses pendataan pelanggan, dan proses pelayanan konsumen yang diterapkan di Xyz BodyCare. Diskusi Interaktif ini dimaksudkan agar data yang diperoleh lebih lengkap dan jelas. Adapun Hasil Diskusi Interaktif diantaranya :

1. Data Konsumen

2. Model Pelayanan konsumen yang dilakukan selama ini.

3. Data dan proses transaki pelanggan

4. Prasyarat dan keuntungan menjadi member

5. Solusi penyelesaian masalah

\section{ANALISIS DAN PEMBAHASAN}

\section{a. Operational CRM}

Digunakan untuk fungsi-fungsi bisnis yang melibatkan customer service, manajemen order, nota/tagihan, atau manajemen dan automasi bagi marketing dan penjualan, serta transaksi-transaksi yang sangat berhubungan dengan Operational CRM. Pada operasional CRM ini dapat diterapkan diantaranya adalah:

1. Loyalty Program Program ini ditujukan untuk meningkatkan loyalitas pelanggan.

2. Prospecting Program Ditujukan untuk memenangkan atau mendapatkan pelanggan-pelanggan baru.

3. Save or Win Back Program Program ini mencoba meyakinkan customer untuk tidak berhenti menggunakan produk/jasa, atau (kalau telah berhenti) untuk menggunakannya kembali.

4. Cross-Sell/Up-Sell Program Dengan menawarkan produk-produk pelengkap (cross sell) atau produkproduk untuk pengembangan produk lama (up sell). 


\section{Journal of Information System, Informatics and Computing}

\section{Struktur Organisasi}

Manajemen strategi $\mathrm{SI} / \mathrm{TI}$ yang diperlukan pada aplikasi CRM Xyz Body Care adalah untuk menciptakan hasil kerja yang optimal dalam mengimplementasikan sistem. Sesuai dengan bisnis perusahaan, maka untuk itu dibuat sesuai dengan kebutuhannya dimana sebagai tim yang akan melaksanakannya dikepalai oleh seorang manajer yang didukung oleh jajaran yang berada dibawahnya adalah Bagian Keuangan, Marketing, Adm.\& IT dan Pelayanan, sesuai Gambar 3 berikut.

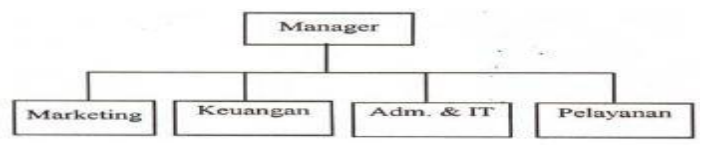
Qambax 3: Struktux Organisasi

\section{WORK BREAKDOWN STRUCURED}

Work Breakdown Structured (WBS) adalah gambaran struktur fungsi dari level tertinggi sampai level rinci, adapun WBS dari Aplikasi CRM pada Salon Body Care yang akan dibangun:

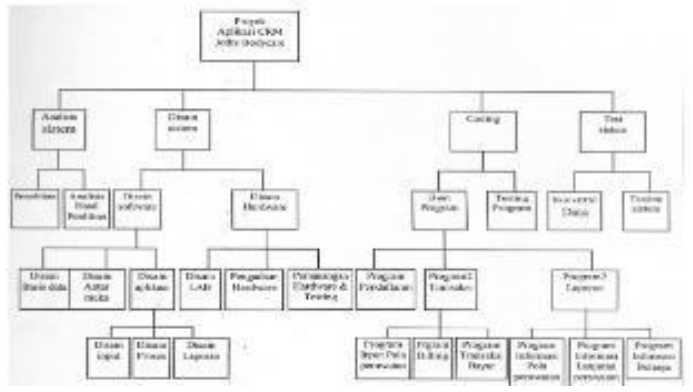

\section{Gambar 1: Work Breakdown Structure Xyz Body Care}

\section{Jadwal Pelaksanaan (Schedule)}

Untuk membuat jadwal pelaksanaan ini sebelumnya ada beberapa kegiatan yang harus dilalui. Estimasi Waktu : Pembuatan estimasi waktu aktivitas ini dibua berdasarkan apa yang ada pada WBS,

\begin{tabular}{|c|c|c|c|}
\hline Task & $\begin{array}{l}\text { Task } \\
\text { sblm }\end{array}$ & $\begin{array}{l}\text { Task } \\
\text { ssdh }\end{array}$ & $\begin{array}{l}\text { Wkt } \\
\text { hari }\end{array}$ \\
\hline litian & & B & 2 \\
\hline isis hasil penelitian & A & $\mathrm{C}, \mathrm{H}$ & 2 \\
\hline in Basisdata & B & $D, G$ & 2 \\
\hline in antar muka & C & $\mathrm{E}$ & 2 \\
\hline in Input & D & $\mathbf{F}$ & 2 \\
\hline in Proses & E & $\mathrm{K}, \mathrm{L}, \mathrm{M}$ & 3 \\
\hline in Laporan & C & $\mathrm{K}, \mathrm{I}, \mathrm{M}$ & 3 \\
\hline in LAN & B & I & 2 \\
\hline fadaan Hardware & $\mathrm{H}$ & $\mathrm{J}$ & 2 \\
\hline asangan Hardware & I & $\mathbf{K}, \mathbf{I}, \mathbf{M}$ & 3 \\
\hline ram Pendaftaran & $F, G, J$ & $\mathrm{O}, \mathrm{Q}$ & 1 \\
\hline I Input pola perawatan & $F, G, J$ & $O, Q$ & 1 \\
\hline ram Billing & $F, G, J$ & $\mathrm{~N}$ & 1 \\
\hline ram Transaksi bayar & $\mathbf{M}$ & O.Q & $\mathbf{1}$ \\
\hline Info Pola perawatan & $\mathrm{K}, \mathrm{L}, \mathrm{N}$ & P & 1 \\
\hline Info kelanjutan rawat & $\mathrm{O}$ & $\mathrm{R}$ & 1 \\
\hline ram Info Belanja & $\mathrm{K}, \mathrm{L}, \mathbf{N}$ & $\mathrm{R}$ & 1 \\
\hline ing Program & $\mathrm{P}, \mathrm{Q}$ & s & 3 \\
\hline versi data & $\mathbf{R}$ & $\mathbf{T}$ & 3 \\
\hline ing sistem & $\mathbf{s}$ & - & 5 \\
\hline
\end{tabular}

dimana pekerjaan tersebut melihat dari level terakhir dari WBS, setelah ditentukan kegiatan yang diambil dari level trakhir WBS.

\section{Diagram Network}

Setelah estimasi waktu proyek sudah selesai dikerjakan, selanjutnya membuat Diagram Netwrok, untuk membuat diagram

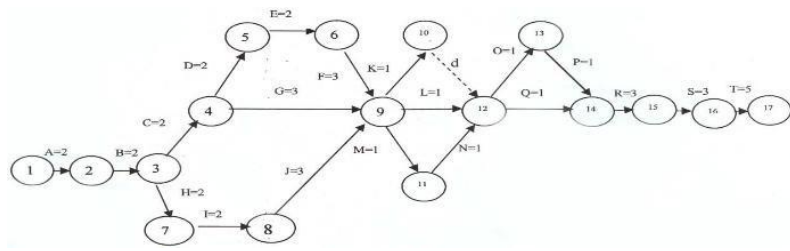

network ini berpedoman pada tabel estimasi proyek dengan Memperhatikan task sesudah dan sebelum, artinya sebuah kegiatan dilakukan sesudah apa kegiatan yang sudah di lakukan.

Gambar 2: Diagram Network CRM xyz Body Care 


\section{Journal of Information System, Informatics and Computing}

\section{Jalur Kritis (Critical Path)}

Jalur kritis (critical path) adalah jalur yang menunjukkan kegiatan kritis dari awal kegiatan sampai dengan akhir kegiatan pada diagram network. Pengertian jalur kritis adalah waktu yang terlama artinya jika pada jumlah lama waku itu proyek tidak selesai maka proyek dianggap selesai tidak tepat waktu sesuai yang direncanakan. Untuk menentukan jalur kritis dengan melihat total dari beberapa jalur yang dapat ditarik dari diagram network kemudian disusun kedalam sebuah tabel dan lama hari kerjanya dijumlahkan sehingga totalnya kita bandingakan satu dengan yang lainnya. $\mathrm{Hal}$ ini dapat dilihat dari dari beberapa jalur yang ditunjukkan pada tabel 2 yang terdiri dari jalur kegiatan kemudian perhatikan total terlama, maka itulah jalur kritisnya. Dalam hal ini yaitu total hari yang terlama adalah 28 hari pada jalur $A, B, C, D, E, F, M, N, O, P, R, S, T$.

\begin{tabular}{|c|c|c|c|c|c|}
\hline \multicolumn{3}{|c|}{ Tabel 2: Daftar Jalur Kegiatan } & 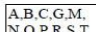 & $2+2+2+3+1+1+1+1+3+3+5$ & 24 hari \\
\hline Jalur & Hari & \begin{tabular}{|l|} 
Tt1 \\
\end{tabular} & \multirow{10}{*}{ 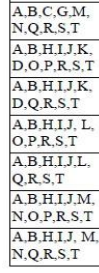 } & \multirow{2}{*}{$2+2+2+3+1+1+1+3+3+5$} & \multirow[t]{2}{*}{23 hari } \\
\hline A,B,C,D,E,F, & $2+3+1+0+1+1+3+3+5$ & 27 hari & & & \\
\hline \begin{tabular}{|l}
$\mathrm{K}, \mathrm{D}, \mathrm{O}, \mathrm{P}, \mathrm{R}, \mathrm{S}$, \\
$\mathrm{A}, \mathrm{B}, \mathrm{C}, \mathrm{D}, \mathrm{E}, \mathrm{F}$,
\end{tabular} & Le- -5 & 26 hari & & $2+2+2+2+3+1+0+1+1+3+3+5$ & \\
\hline K,D,Q,R,S,T & $2^{2+2+2+2+2+3+1+0+1+3+3+3}$ & & & $2+2+2+2+3+1+0+1+3+3+5$ & \\
\hline $\begin{array}{l}\mathrm{A}, \mathrm{B}, \mathrm{C}, \mathrm{D}, \mathrm{E}, \mathrm{F}, \\
\mathrm{L}, \mathrm{O}, \mathrm{P}, \mathrm{R}, \mathrm{S}, \mathrm{T}\end{array}$ & $2+2+2+2+2+3+1+1+1+3+3+5$ & & & & \\
\hline $\begin{array}{l}\text { A,B,C,D,E,F, } \\
\text { L,Q,R,S,T }\end{array}$ & $2+2+2+2+2+3+1+1+3+3+5$ & 26 hari & & $2^{2+2}+2+2+3+1+1+1+3+3+5$ & \\
\hline A,B,C,D,E,F,M & & 28 hari & & $2+2+2+2+3+1+1+3+3+5$ & \\
\hline & $2+2+2+2+2+3+1+1+1+1+3+3+3$ & & & $2+2+2+2+3+1+1+1+1+3+3+5$ & \\
\hline $\begin{array}{l}\mathrm{A}, \mathrm{B}, \mathrm{N}, \mathrm{Q}, \mathrm{L}, \mathrm{E}, \mathrm{S}, \mathrm{T} \\
\mathrm{M}\end{array}$ & $2+2+2+2+2+3+1+1+1+3+3+5$ & 2/ harl & & $2+2+2+2+3+1+1+1+3+3+5$ & \\
\hline $\begin{array}{l}\text { A,B,C,G,K,D, } \\
\mathrm{O}, \mathrm{P}, \mathrm{R}, \mathrm{S}, \mathrm{T}\end{array}$ & $2+2+2+3+1+0+1+1+3+3+5$ & 23 hari & & & \\
\hline $\begin{array}{l}\text { A,B,C,G,K,D, } \\
\text { Q,R,S,T }\end{array}$ & $2+2+2+3+1+0+1+3+3+5$ & 22 hari & Jalur kritis & $\begin{array}{l}=\mathrm{A}, \mathrm{B}, \mathrm{C}, \mathrm{D}, \mathrm{E}, \mathrm{F}, \mathrm{M}, \mathrm{N}, \mathrm{O}, \mathrm{P}, \mathrm{R} \\
=2+2+2+2+2+3+1+1+1+1\end{array}$ & $\begin{array}{l}\mathrm{S}, \mathrm{T} \\
+3+3+5\end{array}$ \\
\hline $\begin{array}{l}\mathrm{A}, \mathrm{B}, \mathrm{C}, \mathrm{G}, \mathrm{L}, \mathrm{O}, \\
\mathrm{P}, \mathrm{R}, \mathrm{S}, \mathrm{T}\end{array}$ & $2+2+2+3+1+1+1+3+3+5$ & 23 hari & & & \\
\hline \begin{tabular}{|l|}
$\mathrm{A}, \mathrm{B}, \mathrm{C}, \mathrm{G}, \mathrm{L}$, \\
$\mathrm{Q}, \mathrm{R}, \mathrm{S}, \mathrm{T}$
\end{tabular} & $2+2+2+3+1+1+3+3+5$ & & & & \\
\hline
\end{tabular}

\section{Schedule}

Jadwal kegiatan diperlihatkan pada Tabel 3 untuk kolom yang diarsir panjangnya disesuaikan dengan jumlah hari kegiatan. Waktu yang dibutuhkan pada jadwal kegiatan ini selama 28 hari, jadi sesuai dengan waktu jalur kritis.

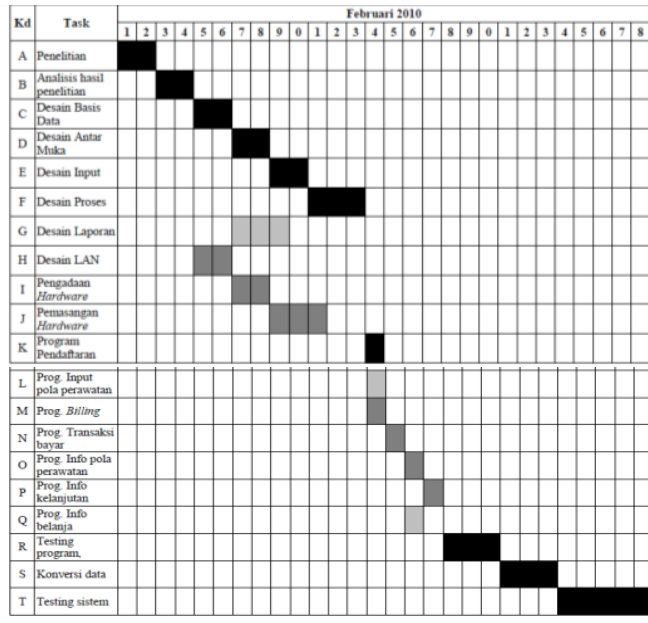

Tabel 3: Schedule Salon Body Care

\section{Alokasi Sumber Daya (Resources)}

Sumber daya terdiri dari 2(dua) macam, yaitu Sumber Daya Manusia (SDM) dan Sumber Daya Alat, dimana kedua sumber daya ini sangat memegang peranan atas keberhasilan proyek yang akan dibangun.

\section{Alokasi Sumber Daya Manusia}

Sumber Daya Manusia yang dipekerjakan pada proyek Aplikasi CRM Xyz Body Care berpedoman pada WBS yaitu ditentukan dari level terendahnya. Kebutuhan sumber daya manusia setelah merujuk ke WBS maka hasilnya seperti yang diuraikan pada Tabel 4 berikut ini.

\begin{tabular}{c|l|l|l|l|}
\hline $\begin{array}{c}\text { Ko } \\
\text { de }\end{array}$ & \multicolumn{1}{|c|}{ Task } & $\begin{array}{c}\text { Wkkt } \\
\text { hari }\end{array}$ & $\begin{array}{c}\text { Jml } \\
\text { SDM }\end{array}$ & Skill \\
\hline A & Penelitian & 2 & 1 & SA \\
\hline B & Analisis hasil penelitian & 2 & 1 & SA \\
\hline C & Disain Basis data & 2 & 1 & SA \\
\hline D & Disain antar muka & 2 & 1 & SA \\
\hline E & Disain Input & 2 & 1 & SA \\
\hline F & Disain Proses & 3 & 1 & SA \\
\hline G & Disain Laporan & 3 & 1 & SA \\
\hline H & Disain LAN & 2 & 1 & SA \\
\hline I & Pengadaan Hardware & 2 & 1 & SA \\
\hline J & Pemasangan Hardware & 3 & 1 & TK \\
\hline K & Program Pendaftaran & 1 & 1 & PR \\
\hline L & Progr Input pola perawatan & 1 & 1 & PR \\
\hline M & Program Billing & I & 1 & PR \\
\hline N & Program Transaksi bayar & 1 & 1 & PR
\end{tabular}

Tabel 4: Alokasi Sumber Daya Manusia

\section{Catatan :}

$\mathrm{SA}=$ System Analyst

TK $=$ Teknisi

JISICOM (Journal of Information System, Informatics and Computing)

http://journal.stmikjayakarta.ac.id/index.php/jisicom Telp.+62-21-3905050, e-mail: jisicom@stmikjayakarta.ac.id, jisicom2017@gmail.com 


\section{Journal of Information System, Informatics and Computing}

$\mathrm{PR}=$ Programmer

$\mathrm{TS}=$ Tester

\section{Kebutuhan Sumber Daya Manusia}

Berdasarkan jadwal pelaksanaan proyek dimana ada beberapa aktivitas terjadi paralel artinya dapat dikerjakan pada waktu yang bersamaan, maka jumlah kebutuhan Sumber daya manusia menurut skillnya dapat disusun sesuai Tabel 5 berikut ini.

\begin{tabular}{|c|c|c|l|}
\hline N & Skill & $\begin{array}{c}\text { Jml } \\
\text { SDM }\end{array}$ & \multicolumn{1}{|c|}{ Keterangan } \\
\hline 1 & System Analis & 3 & $\begin{array}{l}\text { Untuk Peneltian, } \\
\text { Analisis dan Disain }\end{array}$ \\
\hline 2 & Programmer & 3 & $\begin{array}{l}\text { Untuk pembuatan } \\
\text { program aplikasi }\end{array}$ \\
\hline 3 & Tester & 2 & $\begin{array}{l}\text { Untuk testing program, } \\
\text { system, LAN AN }\end{array}$ \\
\hline 4 & Teknisi & 1 & Untuk Instalasi LAN \\
\hline
\end{tabular}
Manusia

Tabel 5: Kebutuhan Sumber Daya

\section{Alokasi Sumber Daya Alat Operasional}

Untuk operasional aplikasi CRM Xyz

Body Care diperlukan peralatan-peralatan yang dimuatpada Tabel 6 berikut ini.

\begin{tabular}{|c|c|}
\hline Alat & Keterangan \\
\hline $\begin{array}{l}\text { Perangkat Keras } \\
\text { 1. PC (1 unit untuk Server) } \\
\text { 2. HP LaserJet Printer } \\
\text { 3. PC } 2 \text { unit untuk terminal }\end{array}$ & $\begin{array}{l}\text { W/ database server } \\
\text { Operasional cetakan } \\
\text { Sebagai host }\end{array}$ \\
\hline $\begin{array}{l}\text { Perangkat Lunak } \\
\text { 1. Ms SQI Server } 2000 \\
\text { 2. Ms Visual Basic 6.0 } \\
\text { 3. Crystal Report 8.0 }\end{array}$ & $\begin{array}{l}\text { w/ database server } \\
\text { w/ pengembangan aplikasi } \\
\text { w/ generate laporan }\end{array}$ \\
\hline $\begin{array}{l}\text { LAN } \\
\text { 1. Switch (1 unit) } \\
\text { 2. Network peripheral }\end{array}$ & $\begin{array}{l}\text { w/ membagi ke host } \\
\text { w/ pendukung LAN }\end{array}$ \\
\hline
\end{tabular}

\section{Alokasi Sumber Daya Alat}

Untuk membangun aplikasi CRM Xyz Body Care diperlukan peralatan-peralatan yang dimuat pada Tabel 7 berikut ini

\begin{tabular}{|l|l|}
\hline Alat & Penjelasan \\
\hline PC Server set & Sebagai database server \\
\hline HP LaserJet Printer & Untuk pencetakkan dokumen \\
\hline PC terminal & Sebagai host pembuatan program \\
\hline Perangkat LAN & Pendukung kebutuhan LAN \\
\hline
\end{tabular}

Tabel 7: Peralatan Untuk Membangun CRM

Penyusunan biaya dibagi menjadi kelompokkelompok tenaga kerja, pembelian alat, dan penyewaan alat

\section{Biaya Tenaga Kerja}

Biaya yang diperlukan untuk Tenaga kerja adalah yang ditunjukkan pada Tabel 8 berikut ini:

\begin{tabular}{|c|c|c|c|c|c|}
\hline $\begin{array}{c}\text { Tenaga } \\
\text { Kerja }\end{array}$ & $\mathbf{j}$ & Task & Durasi & $\begin{array}{c}\text { Tarif/ } \\
\text { hari }\end{array}$ & $\underbrace{\text { Jumla }}_{\text {Buaylaha }}$ \\
\hline $\begin{array}{l}\text { System } \\
\text { dnalyst }\end{array}$ & 1 & $A, B, C, D, E \& F$ & 13 & 600.000 & 7.800 .000 \\
\hline \begin{tabular}{|l} 
System \\
Analysst
\end{tabular} & 1 & G & 3 & 600.000 & 1.800 .000 \\
\hline $\begin{array}{l}\text { System } \\
\text { Analyst }\end{array}$ & 1 & $H \& I$ & 4 & 600.000 & 2.400 .000 \\
\hline Programmer & 1 & $\mathrm{~K}$ & 1 & 500.000 & 500.000 \\
\hline \begin{tabular}{|l|} 
Programmer \\
\end{tabular} & 1 & I \& $Q$ & 2 & 500.000 & 1.000 .000 \\
\hline \begin{tabular}{|l|} 
Programmer \\
\end{tabular} & 1 & $M, N, O \& P$ & 4 & 500.000 & 2.000 .000 \\
\hline Tester & 2 & $R, S \& T$ & 11 & 300.000 & 6.600 .000 \\
\hline Teknisi & 1 & $J$ & 3 & 300.000 & 900.000 \\
\hline
\end{tabular}

Tabel 8: Biaya Untuk Tenaga Kerja

\section{Biaya Beli Alat}

Biaya yang diperlukan untuk Pembelian alat yang akan digunakan untuk operasional, adalah yang ditunjukkan pada Tabel 9 berikut ini.

Tabel 9: Biaya Untuk Pembelian alat

\begin{tabular}{|c|c|c|c|}
\hline Komponen/alat & $J \mathbf{m I}$ & Harga & $\begin{array}{c}\text { Jumlah } \\
\text { Biaya }\end{array}$ \\
\hline $\begin{array}{l}\text { PC Server + } \\
\text { Monitor }\end{array}$ & 1 & 5.200 .000 & 5.200 .000 \\
\hline $\begin{array}{l}\text { HP LaserJet } \\
\text { Printer }\end{array}$ & 1 & 5.000 .000 & 5.000 .000 \\
\hline PC terminal & 2 & 3.500 .000 & 7.000 .000 \\
\hline $\begin{array}{l}\text { Microsofi SQI } \\
\text { Server } 2000\end{array}$ & 1 & 3.500 .000 & 3.500 .000 \\
\hline $\begin{array}{l}\text { Microsoft Visual } \\
\text { Basic 6.0 }\end{array}$ & 1 & 2.500 .000 & 2.500 .000 \\
\hline Crystal Report 8.0 & 1 & 1.500 .000 & 1.500 .000 \\
\hline Switch & 1 & 2.000 .000 & 2.000 .000 \\
\hline $\begin{array}{l}\text { Network peripheral } \\
\text { (Paket) }\end{array}$ & 1 & 4.000.000 & 4.000.000 \\
\hline 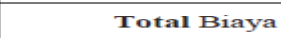 & & is & 28.700 .000 \\
\hline
\end{tabular}

JISICOM (Journal of Information System, Informatics and Computing)

http://journal.stmikjayakarta.ac.id/index.php/jisicom Telp.+62-21-3905050, e-mail: jisicom@stmikjayakarta.ac.id, jisicom2017@gmail.com 


\section{Biaya Sewa}

Biaya yang diperlukan untuk sewa alat yang digunakan pada aktivitas diproyek adalah sesuai ditunjukkan pada Tabel 10 berikut ini

\begin{tabular}{|c|c|c|c|c|}
\hline $\begin{array}{c}\text { Komponen/ } \\
\text { alat }\end{array}$ & Jml & $\begin{array}{c}\text { Lama } \\
\text { sewa }\end{array}$ & $\begin{array}{c}\text { Harga/ } \\
\text { hari }\end{array}$ & $\begin{array}{c}\text { Jumlah } \\
\text { Biaya }\end{array}$ \\
\hline PC Server set & 1 & 20 & 100.000 & 2.000 .000 \\
\hline $\begin{array}{l}\text { HP LaserJet } \\
\text { Printer }\end{array}$ & 1 & 20 & 100.000 & 2.000 .000 \\
\hline PC terminal & 2 & 20 & 75.000 & 1.500 .000 \\
\hline $\begin{array}{l}\text { Perangkat } \\
\text { LAN }\end{array}$ & 1 & 20 & 40.000 & 800.000 \\
\hline \multicolumn{4}{|c|}{ Total Biaya Sewa Alat } & 6.300 .000 \\
\hline
\end{tabular}

Tabel 10: Biaya Penyewaan Alat Untuk Aktivitas

\section{KESIMPULAN}

Work Breakdown Structured (WBS) merupakan sebuah struktur yang paling awal harus dibuat. Pada perencanaan proyek, WBS yang dibuat secara rinci yang dimulai dari fungsi-fungs yang besar kemudian dipecah menjadi fungsifungsi yang sangat rinci sesuai proyek CRM Xyz

\section{REFERENSI}

[1] Destiana, H., \& Hadidah, A. (2016). Sistem Informasi Penjualan Accessories Berbasis Web. Paradigma, XVIII(1), 2837.

https://ejournal.bsi.ac.id/ejurnal/index.ph p/paradigma/article/view/872

[2] Effendi, A. (2013). Dokumen Karya Ilmiah | Tugas Akhir | Program Studi Sistem Informasi - S1 | Fakultas Ilmu Komputer | Universitas Dian Nuswantoro Semarang 2013. Rancang Bangun E-CRM Pada Pasar Murah Solo, 1, 3-4.

[3] Fardhani, K. F., Rachmawati, I., \& Prabowo, F. S. (2016). Pengaruh Customer Relationship Management ( $\mathrm{Crm}$ ) Terhadap Loyalitas Pelanggan English First Samarinda the Effect of Customer Relationship Management ( Crm ) on Customer' S Loyalty of English First Samarinda. E-Proceeding of Management, 3(2), 986-989.

\section{Rekapitulasi Biaya}

Biaya keseluruhan yang diperlukan untuk Proyek dengan menjumlah seluruh biaya, yaitu sesuai yang ditunjukkan pada Tabel 11 berikut ini

Tabel 11: Rekapitulasi Biaya Proyek

\begin{tabular}{|c|c|}
\hline Indikator & Jumlah \\
\hline Biaya Tenaga Kerja & 23.000 .000 \\
\hline Biaya Pembelian Alat & 28.700 .000 \\
\hline Biaya Sewa Alat & 6.300 .000 \\
\hline Total Biaya & 58.000 .000 \\
\hline
\end{tabular}

Body Care ternyata mampu memberikan estimasi yang paling tidak mendekati kebutuhan untuk sisi jadwal pelaksanaan (Schedule), sumber daya (Resources), rencana biaya (Cost), analisis risiko (Risk Analysis) dan bentuk perubahan manajemen (Change Management) untuk sebuah proyek.

[4] Manu, G., \& Tugil, H. (2020). Perancangan Sistem Informasi Manajemen Ekstrakurikuler (Sime) Berbasis Web. Jurnal Pendidikan Teknologi Informasi (JUKANTI), 3(1), 14-20. https://doi.org/10.37792/jukanti.v3i1.91 [5] Janiar Puspa Wildyaksanjani dan Dadang Sugiana, (2018). Strategi Customer Relationship Management (crm) PT Angkasa Pura II (Persero).

[5] Mary, T., \& Juita, E. (2017). Ibm INFORMATION SYSTEMS ASSOCIATE CLINICS In The REGION DOWN VERA PUSKEMAS PADANG. Jurnal Sinergitas PkM \& CSR, 2(1), 1523.

[6] Maudi, M., Nugraha, A., \& Sasmito, B. (2014). Desain Aplikasi Sistem Informasi Pelanggan Pdam Berbasis Webgis (Studi Kasus: Kota Demak). Jurnal Geodesi Undip, 3(3), 98-110.

[7] Maulana, S. M., Susilo, H., \& Riyadi. (2015). Implementasi E-Commerce Sebagai 
Media Penjualan Online. Jurnal Administrasi Bisnis, 29(1), 1-9.

[8] Puspa Wildyaksanjani, J., \& Dadang Sugiana, dan. (2018). Strategi Customer Relationship Management (CRM) PT Angkasa Pura II (Persero). Jurnal Kajian Komunikasi, 6(1), 10-23.

[9] Soediono, B., Mustofa, A., Informatika, T., \& Nuswantoro, U. D. (2014). Analisis Dan Perancangan Sistem Informasi EEducation Berbasis Web Di Sma Pembangunan Mranggen. Journal of
Chemical Information and Modeling, 53(2004), 1-6.

[10]Solihin, H. H. (2017). Perancangan Sistem Informasi Penerimaan Siswa Baru Berbasis Web (Studi Kasus: Smp Plus Babussalam Bandung). Infotronik: Jurnal Teknologi Informasi Dan Elektronika, $1(1), \quad 54$. https://doi.org/10.32897/infotronik.2016. 1.1 .9 